\title{
Patients' attitude towards undergraduate medical students at university charity teaching hospital in Sudan
}

\author{
Awad Ali M. Alawad *, Faisal H. Younis \\ Assistant Professor of Surgery, Faculty of Medicine, University of Medical Sciences and Technology, Sudan \\ *Corresponding author E-mail: awadali82@ hotmail.com
}

\begin{abstract}
Background: The cooperation of patients and their acceptance to involve medical students in their care is vital to clinical education. Objective: To explore the attitudes of patients towards medical students at University charity teaching hospital, and to explore the determinants of those attitudes.

Methods: This cross-sectional study was conducted at University charity teaching hospital affiliated to University of Medical Sciences and Technology (UMST). Four hundred and thirty-two patients were interviewed between January and December 2013 using a structured questionnaire.

Results: Four hundred and thirty-two patients had responded to all questions they were asked. Of the patients interviewed, $95.2 \%$ approved the presence of medical students during the medical consultation. $79.8 \%$ of the patients agreed to be examined by students in the presence of a doctor, while $33.5 \%$ gave agreement even in the absence of a doctor. More than half of the patients think that it is important that students examine patients as part of their training and $18 \%$ of them were not sure about the importance of clinical examination.

Conclusion: The study concluded overall positive attitudes to the medical students' involvement by patients. Patients preferred lower number of students to be involved; however, few were aware of their rights.
\end{abstract}

Keywords: Bedside Teaching, Clinical Education, Patients' Acceptability.

\section{Introduction}

Worldwide, patients are the cornerstone of bedside teaching of medical students (Ferguson et al. 2013). Contact with patients remains a vital component in the education of medical students. Encounters with patients can promote contextual and clinical learning, improve communication and professional skills and initiate the development of a future doctor-patient relationship. $\mathrm{Pa}$ tients' willingness to cooperate and contribute to the education and training of medical students provide better teaching opportunities for students at most levels of patient care (Marwan et al. 2012).

Medical education researchers suggested that bedside teaching is affected by four factors: teaching curriculum, clinical supervisors, medical students and patients (Sayed-Hassan et al. 2012). Patients are active participants in choosing their care, leading to difficulty in training students if patients decline their involvement. With increased focus on patients' rights and informed consent, patients can now choose whether to have medical students present during their consultations (Marwan et al. 2012).

Studies had been conducted to know the feelings of the patients toward the involvement of medical students in their care. It has been noticed in many hospitals worldwide that a minority of patients refuse, or feel negative about the involvement of medical students in their care (Simons et al. 1995, Hartz \& Beal 2000, Rizk et al. 2002, O'Flynn \& Rymer 2003, Mavis et al. 2006, Thurman et al. 2006, Passaperuma et al. 2008,). However, the comfort levels of patients regarding medical students found to be different between patients of different specialties. For example, Urology patients reported higher comfort levels with male stu- dents, while Obstetrics/Gynecology patients showed higher comfort levels with female students (Fortier et al. 2006, Passaperuma et al. 2008).

At the UMST, medical students enter the undergraduate medical programme to read for the Bachelor of Medicine and Bachelor of Surgery (MBBS) degree over a period of five years. Formal clinical training takes place during the latter three years, during which time medical students are passed through a series of hospital rotations and clinical attachments in the main medical and surgical disciplines. During these rotations, medical students are exposed to patient care and are taught interviewing and examination skills. The bedside teaching in the Faculty of Medicine of University of Medical Sciences and Technology (UMST) is designed to allow students to spend a lot of time in hospitals to learn and practice clinical skills, thus exposed to a larger number of patients in various specialties. However, patients' acceptability toward the presence of medical students in the teaching hospital of UMST was not assessed. Our objectives are to determine if patients' acceptability of medical students differs according to the patients' sociodemographic characteristics and to assess if the student's gender has an effect on the patients' acceptability. We also aim to explore the attitudes of patients towards medical students at University charity teaching hospital, and to explore the determinants of those attitudes thus discussing possible implications applicable to clinical teaching to improve the bedside teaching of medical students. 


\section{Methods}

This is a cross-sectional descriptive study that relied on conducting face-to-face interviews using a structured questionnaire with a random sample of patients admitted to University charity teaching hospital, University of Medical Sciences and Technology, Khartoum, Sudan. This study was carried out during the period from beginning of January to end of December 2013.

The questionnaire was designed specifically for the purpose of the study having consulted the medical literature of similar studies (Hartz \& York et al. 1995, Beal 2000, Grasby \& Quinlivan 2001, Jackson et al. 2003, Saeed et al. 2007, Abdulghani et al. 2008, Malhotra \& Hosdurga 2010, Carmody et al. 2011). The questionnaire was piloted on a sample of 15 patients to ensure face validity and clarity. Minor changes were made; namely rewording two questions. Those interviews were excluded from the analysis. The questionnaire contained 18 items, including demographic and socio-economic data and patients' attitudes toward medical students and their preferences when involving medical students in the clinical examination. Face-to-face interviews using the questionnaire were conducted by three senior house officers. Interviews took place at surgical wards.

Data were entered into a Microsoft Excel spreadsheet and the statistical analysis was conducted using SPSS (Version 17). Statistical analysis was carried out using descriptive and analytical statistics. Simple frequencies and cross tabulation were done. Chi square test was used for proportions. Stratification for the patient's sex and educational level was done when relevant. $\mathrm{P}$ value of less than 0.05 was considered statistically significant.

The consent of the patients was obtained. A full explanation of the purposes and nature of the study was conveyed to them. The potential participants were clearly assured that their participation in this study is voluntary any data obtained would be treated confidentially and for the purpose of the research only.

\section{Results}

Four hundred and thirty two patients were interviewed in this study. None of the patients approached refused to participate. General characteristics of patients recruited in the study are presented in Table 1 . The average age of patients was 40.7 years, and $36.3 \%$ of them had high school or university level education. Among all study participants, 243 (56.3\%) were males and 260 $(60.2 \%)$ were married. The majority of them were Sudanese (395; $91.4 \%)$.

Table 1: Sociodemographic Characteristics of Patients in University Charity Teaching Hospital, Khartoum, Sudan 2013 (N=432)

\begin{tabular}{ll}
\hline Item & Patients No (\%) \\
\hline Age & \\
Mean & 40.7 \\
Sex & \\
Male & $243(56.3 \%)$ \\
Female & $189(43.7 \%)$ \\
Marital Status & $260(60.2 \%)$ \\
$\quad$ Married & $172(39.8 \%)$ \\
$\quad$ Not married & \\
Educational Level & $72(16.8 \%)$ \\
$\quad$ Illiterate & $66(15.2 \%)$ \\
Primary & $137(31.7 \%)$ \\
$\quad$ Secondary & $157(36.3 \%)$ \\
$\quad$ University & $395(91.4 \%)$ \\
Nationality & $37(8.6 \%)$ \\
$\quad$ Sudanese & \\
$\quad$ Non Sudanese &
\end{tabular}

Table 2 summarizes the patients' attitudes towards the education of medical students which seemed generally positive. Of the patients interviewed, $95.2 \%$ approved the presence of medical students during the medical consultation. Majority $(90.7 \%)$ of the study participants responded that they would not refuse if students asked to take medical history and personal details. Most of the participants $(89.5 \%)$ preferred to be informed in advance that a medical student will be present during clinical examination. Of all patients, $79.8 \%$ approved to be examined by a medical student in the presence of a supervisor, while $33.5 \%$ approved the examination in the absence of a supervisor.

One hundred and thirty one $(30.1 \%)$ of the patients was aware of their right to refuse or accept the presence of medical students during the clinical encounter. Among 432 study participants, (74\%) would prefer students with their gender. When patients were asked about their acceptance regarding the presence of medical students in the operation theatre if their condition required a surgical intervention, $11.2 \%$ (48) of them refused students to be present. $72 \%$ of the participants refused students to perform diagnostic procedures for them. General appearance of students affects the decision of the majority of the participants (93\%) to cooperate with them.

Table 2: Patients' Reactions toward the Presence of Medical Students in University Charity Teaching Hospital, Khartoum, July 2013 (N=432)

\begin{tabular}{lll}
\hline Question & $\begin{array}{l}\text { Yes } \\
\text { Freq. \% }\end{array}$ & $\begin{array}{l}\text { No } \\
\text { Freq. \% }\end{array}$ \\
\hline $\begin{array}{l}\text { Do you approve the existence of medi- } \\
\text { cal students during consultation? }\end{array}$ & $412(95.2 \%)$ & $20(4.8 \%)$ \\
$\begin{array}{l}\text { Do you prefer to be informed in ad- } \\
\text { vance that a medical student will be } \\
\text { present during your clinical examina- } \\
\text { tion? }\end{array}$ & $387(89.5 \%)$ & $45(10.5 \%)$ \\
$\begin{array}{l}\text { Would you permit medical students to } \\
\text { take your medical history and personal } \\
\text { details from you? }\end{array}$ & $392(90.7 \%)$ & $40(9.3 \%)$ \\
$\begin{array}{l}\text { Do you accept the presence of students } \\
\text { during your physical examinations? }\end{array}$ & $361(83.4 \%)$ & $71(16.6 \%)$ \\
$\begin{array}{l}\text { Would you permit medical students to } \\
\text { examine you with the presence of a } \\
\text { doctor? }\end{array}$ & $345(79.8 \%)$ & $87(20.2 \%)$ \\
$\begin{array}{l}\text { Would you permit medical students to } \\
\text { examine you without the presence of a } \\
\text { doctor? }\end{array}$ & $145(33.5 \%)$ & $287(66.5 \%)$ \\
$\begin{array}{l}\text { Do you prefer that the student be of } \\
\text { your gender? }\end{array}$ & $320(74 \%)$ & $112(26 \%)$ \\
$\begin{array}{l}\text { Does general appearance and manner of } \\
\text { a student affect your co-operation with } \\
\text { them? }\end{array}$ & $402(93 \%)$ & $30(7 \%)$ \\
$\begin{array}{l}\text { Do you think that you have the right to } \\
\text { approve or disapprove the existence of } \\
\text { medical students during the clinical } \\
\text { encounter? }\end{array}$ & $131(30.1 \%)$ & $301(69.9 \%)$ \\
$\begin{array}{l}\text { Would you permit medical students to } \\
\text { be present in the operation room if you } \\
\text { were having a surgery? }\end{array}$ & $384(88.8 \%)$ & $48(11.2 \%)$ \\
$\begin{array}{l}\text { Would you permit medical students to } \\
\text { perform diagnostic/other procedures on } \\
\text { you (e.g. inserting catheter, endoscopy } \\
\text {.etc.)? }\end{array}$ & $121(28 \%)$ & $311(72 \%)$ \\
\hline
\end{tabular}

A larger proportion of patients who were more educated had negative attitudes than less educated patients. Male patients were more likely to accept male students, while female patients preferred female students more (Table 3). The odds of females to prefer female students appeared higher than that of males to prefer male students to care for them COR $(95 \%$ CI); $(1.00,1.93)$.

Patients' preferences regarding the teaching of medical students are shown in Table 4. Patients preferred a smaller number of students during the clinical round $(67.9 \%$ of patients preferred the presence of a maximum of 8 medical students) and would prefer to be examined by one or two students only $(87.2 \%)$. More than half of the patients think that it is important that students examine patients as part of their training and $18 \%$ of them were not sure about the importance of clinical examination. 


\section{Discussion}

This study contributed to the understanding of Sudanese patients attitudes towards the involvement of medical students in clinical teaching, as reported by those seen at University charity teaching hospital. It is worthy to note that the services in this charity hospital are completely free of charge.

Table 3: Patients' Gender Preference for Students Correlated To Sex and Education Level in UCTH, Khartoum, Sudan 2013 (N=432)

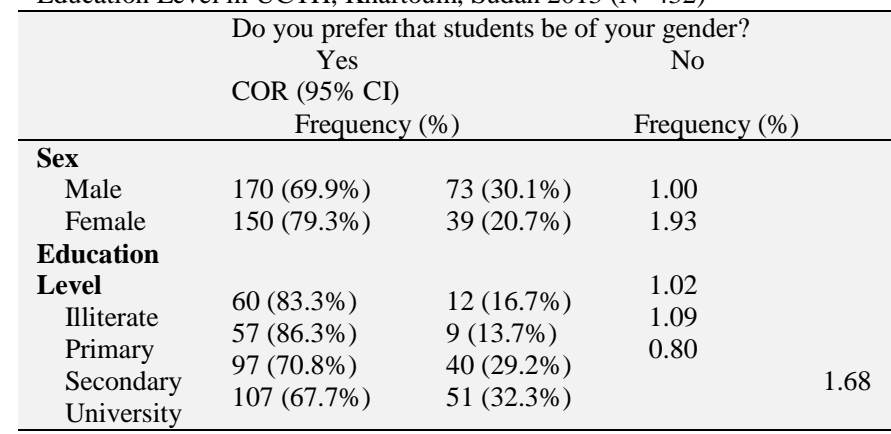

Table 4: Patients' Views of Medical Student Involvement during Their Consultation, UCTH, Khartoum, Sudan 2013

\begin{tabular}{ll}
\hline Item & $\begin{array}{l}\text { Patients No } \\
(\%)\end{array}$ \\
\hline $\begin{array}{l}\text { What is your preferred number of students to exist during } \\
\text { clinical consultation? }\end{array}$ & $\begin{array}{l}115 \\
(27.9 \%)\end{array}$ \\
$1-3$ & 280 \\
$4-8$ & $(67.9 \%)$ \\
& $22(4.2 \%)$ \\
What is your preferred number of students to examine you & \\
during clinical consultation? & 301 \\
$1-2$ & $(87.2 \%)$ \\
$3-6$ & $40(11.5 \%)$ \\
6 or more & $4(1.3 \%)$ \\
& \\
How important for the future training of doctors do you \\
think it is that medical students examine patients?
\end{tabular}

Overall, the degree of acceptance of medical students was high, similarly to what was reported in many other studies from developed countries and the Arab World (Abdulghani et al. 2008, Marwan et al. 2012, Sayed-Hassan et al. 2012, Temesgen 2013). The majority of our participants would allow medical students to present during their consultations, take medical history and perform clinical examination in the presence of a doctor. This high allowance might be due to the minimal direct contact between the patient and the student, and minimal involvement of students in providing medical care. Moreover, it was demonstrated in previous studies that patients learn more about their condition when the doctor teaches the students (Price et al. 2008).

Abdulghani and colleagues reported that $45.1 \%$ of patients believed that they had not the right to refuse medical students (Abdulghani et al. 2008). The study of Chipp and colleagues showed that $89 \%$ of patients admitted that they would expect to have their permission sought before seeing a student (Berry et al 2003). Although the need to get patients' consent is a must (Barnett et al. 2009), our study unfortunately revealed that patient consent is simply absent as more than $89 \%$ of patients were indeed unaware of their rights to refuse or accept the active involvement of the medical students. This issue is very critical, as the need to humanize the medical education is very evident, especially in settings such as ours where patients are the main educational tools.

More than $90 \%$ of the study participants responded that they would not object if students took their medical history. This high allowance might be due to the minimal direct contact between the patient and the student, and minimal involvement of students in providing medical care. A minority of our participants would refuse students to examine them with the presence of a supervising doctor; however, this refusal reported to be very high (almost two thirds of the participants) when the patients were asked if they would permit medical students to examine them without a doctor. We share a reason given from Marlborough hospital and; most common reasons for objecting against students' involvement in physical examination were privacy concerns and poorer quality of care (Mollo et al. 2012).

Of great interest in this work is that differences in attitudes were not only related to the sex of the patients but was also related to their educational level. This is contrary to the study of Shah-Khan and colleagues in Chicago that found no relationship between the degree of educational attainment and the attitude of patients towards medical students (Saeed et al. 2007). Female patients admitted to surgical ward were more likely to prefer female students to care for them. The finding of this study on gender preference is in line with the findings of a several studies done (Adams et al. 1999, Passaperuma et al. 2008, Carmody et al. 2011, Siwe et al. 2012). This implies that female students have more chance to be accepted in gynecology and obstetrics wards than male students. Though it was not statistically significant, it seems more educated patients were more likely to have a negative attitude to students in than less educated patents.

A study in the UK found out that patients were gaining from learning about their conditions while students discussed about their problem with their teachers; personal satisfaction from helping students to learn and receiving "gifts" such as personal gratitude (Temesgen 2013). However, clinical teachers and students in Sudan are discussing in English during bed-side teaching using lots of medical terms which is totally difficult to understand by most admitted patients. This may be the other cause for patients' resistance to students' involvement and one of the barriers to efforts directed producing skilled health professionals.

Our study also reported patients' preferences with regard to the scale of medical students' involvement such as the number of students around the bed during the clinical consultation; as well as with regard to the desirable number of students actually examining the patient. Sweeney and colleagues suggested that it is the duty of supervising doctor to be aware of the patients' preference taking into accounts the fears and concerns (Sweeney et al. 2010). Our study showed that most of the patients preferred existence of small number of students (maximum 8 students) during clinical consultation. In our faculty, we face the dilemma of large number of students with small groups as large as 10 students during clinical round. More than half of the patients were aware about the importance of clinical training for medical students.

\section{Conclusion}

Sudanese patients showed overall positive attitudes towards the involvement of medical students. Patient's sex as well as their education level determined their attitudes and preferences. Other factors include general appearance and gender of the students. Patients preferred lower number of students to be involved; however, few were aware of their rights. A more ethical and professional environment and practices are urgently needed in our setting. Patients, students as well as clinical teachers need to learn about the ethics of patients' involvement in medical teaching. . On the other hand, medical education stakeholders are advised to work on improving patients' attitude towards the nature of medical education.

\section{References}

[1] Abdulghani HM, Al-Rukban MO \& Ahmad SS (2008): Patient attitudes towards medical students in Riyadh, Saudi Arabia. Educ Health (Abingdon) 21, 69 
[2] Adams DS, Adams LJ \& Anderson RJ (1999): The effect of patients' race on their attitudes toward medical students' participation in ambulatory care visits. Acad Med 74, 1323-1326.

[3] Barnett AT, Cawich SO, Crandon IW, Lindo JF, Gordon-Strachan G, Robinson D \& Ranglin D (2009): Informed consent from patients participating in medical education: a survey from a university hospital in Jamaica. BMC Res Notes 2, 252.

[4] Berry RE, Jr., O'Dell K, Meyer BA \& Purwono U (2003): Obtaining patient permission for student participation in obstetric-gynecologic outpatient visits: a randomized controlled trial. Am J Obstet Gynecol 189, 634-638.

[5] Carmody D, Tregonning A, Nathan E \& Newnham JP (2011): Patient perceptions of medical students' involvement in their obstetrics and gynaecology health care. Aust N Z J Obstet Gynaecol 51, 553-558.

[6] Ferguson LM, Ward H, Card S, Sheppard S \& McMurtry J (2013): Putting the 'patient' back into patient-centred care: an education perspective. Nurse Educ Pract 13, 283-287.

[7] Fortier AM, Hahn PM, Trueman J \& Reid RL (2006): The acceptance of medical students by women with gynaecology appointments. $J$ Obstet Gynaecol Can 28, 526-530.

[8] Grasby D \& Quinlivan JA (2001): Attitudes of patients towards the involvement of medical students in their intrapartum obstetric care. Aust N Z J Obstet Gynaecol 41, 91-96.

[9] Hartz MB \& Beal JR (2000): Patients' attitudes and comfort levels regarding medical students' involvement in obstetrics-gynecology outpatient clinics. Acad Med 75, 1010-1014

[10]Jackson A, Blaxter L \& Lewando-Hundt G (2003): Participating in medical education: views of patients and carers living in deprived communities. Med Educ 37, 532-538.

[11]Malhotra RK \& Hosdurga G (2010): Patients' attitudes towards the involvement of medical students during induction of regional anesthesia. Local Reg Anesth 3, 73-76.

[12] Marwan Y, Al-Saddique M, Hassan A, Karim J \& Al-Saleh M (2012): Are medical students accepted by patients in teaching hospitals? Med Educ Online 17, 17172.

[13]Mavis B, Vasilenko P, Schnuth R, Marshall J \& Jeffs MC (2006) Medical students' involvement in outpatient clinical encounters: a survey of patients and their obstetricians-gynecologists. Acad Med 81, 290-296.

[14]Mollo EA, Reinke CE, Nelson C, Holena DN, Kann B, Williams N, Bleier J \& Kelz RR (2012): The simulated ward: ideal for training clinical clerks in an era of patient safety. J Surg Res 177, e1-6.

[15]O'Flynn N \& Rymer J (2003): Consent for teaching: the experience of women attending a gynaecology clinic. Med Educ 37, 1109-1114.

[16]Passaperuma K, Higgins J, Power S \& Taylor T (2008): Do patients comfort levels and attitudes regarding medical student involvement vary across specialties? Med Teach 30, 48-54.

[17]Price R, Spencer J \& Walker J (2008): Does the presence of medical students affect quality in general practice consultations? Med Educ 42, 374-381.

[18]Rizk DE, Al-Shebah A, El-Zubeir MA, Thomas LB, Hassan MY \& Ezimokhai M (2002): Women's perceptions of and experiences with medical student involvement in outpatient obstetric and gynecologic care in the United Arab Emirates. Am J Obstet Gynecol 187, 10911100.

[19]Saeed F, Kassi M, Ayub S, Rehman R, Kasi PM \& Rizvi JH (2007): Factors influencing medical student participation in an obstetrics and gynaecology clinic. J Pak Med Assoc 57, 495-498.

[20]Sayed-Hassan RM, Bashour HN \& Koudsi AY (2012): Patient attitudes towards medical students at Damascus University teaching hospitals. BMC Med Educ 12, 13.

[21]Simons RJ, Imboden E \& Martel JK (1995): Patient attitudes toward medical student participation in a general internal medicine clinic. $J$ Gen Intern Med 10, 251-254.

[22] Siwe K, Bertero C \& Wijma B (2012): Unexpected enlightening of a "female world". Male medical students' experiences of learning and performing the first pelvic examination. Sex Reprod Healthc 3, 123 127.

[23] Sweeney K, Magin P \& Pond D (2010): Patient attitudes - training students in general practice. Aust Fam Physician 39, 676-682

[24]Temesgen WA (2013): Patients' attitude towards medical students involvement in their health care at Tikur Anbessa Specialized Hospital, Addis Ababa, Ethiopia, 2010. Ethiop J Health Sci 23, 158164.

[25]Thurman AR, Litts PL, O'Rourke K \& Swift S (2006): Patien acceptance of medical student participation in an outpatient obstetric/gynecologic clinic. J Reprod Med 51, 109-114.

[26]York NL, DaRosa DA, Markwell SJ, Niehaus AH \& Folse R (1995): Patients' attitudes toward the involvement of medical students in their care. Am J Surg 169, 421-423. 